\title{
Learning from Engineers to Develop a Model of Disciplinary Literacy in Engineering (Year 3)
}

\section{Theresa Green, Utah State University - Engineering Education}

Theresa Green is a graduate student at Utah State University pursuing a PhD in Engineering Education. Her research interests include K-12 STEM integration and improving diversity and inclusion in engineering.

\section{Dr. Angela Minichiello P.E., Utah State University}

Angela Minichiello is an assistant professor in the Department of Engineering Education at Utah State University (USU) and a registered professional mechanical engineer. Her research examines issues of access, diversity, and inclusivity in engineering education. In particular, she is interested in engineering identity, problem-solving, and the intersections of online learning and alternative pathways for adult, nontraditional, and veteran undergraduates in engineering.

\section{Dr. Amy Wilson-Lopez, Utah State University - Engineering Education}

Amy Wilson-Lopez is an associate professor at Utah State University who studies culturally responsive engineering and literacy-infused engineering with linguistically diverse students.

\section{Dr. Christina Marie Hartman, Utah State University}

Dr. Christina Hartman is an independent researcher working with teams from Utah State University.

\section{Jared W Garlick, Utah State University}

Jared Garlick is a Graduate Student in the Secondary Education Master's of Education (MEd) program through the Emma Eccles Jones College of Education and Human Services. Research interests include argumentation in science and engineering and the benefit they play in developing literacy in specific content areas. 


\section{Learning from Engineers to Develop a Model of Disciplinary Literacy in Engineering (Year 3)}

\section{Project Overview}

To broaden participation in engineering and improve the accessibility of high quality curricular materials that reflect the authentic nature of the engineering discipline, new approaches to teaching engineering at the K-12 and undergraduate education levels must be explored. One approach to introducing students to rigorous, discipline-specific content is through the use of Disciplinary Literacy Instruction (DLI). DLI is an instructional approach that equips students to utilize the evaluative frameworks and reading and writing strategies that are employed by expert practitioners in a particular discipline [1].

Models of DLI for K-12 instruction have been introduced in subjects such as history [2], math [3], and science [4], but there has been little research exploring a model for DLI in engineering. Thus, this project aims to develop a model of DLI in engineering that can be used in both K-12 and undergraduate engineering settings. This model of DLI will be informed by the strategies that practicing engineers employ while reading, writing, interpreting, and evaluating various textual genres at their workplace. This research project explores the literacy practices of engineers across four disciplines of engineering: electrical/computer, mechanical/aerospace, civil/environmental, and chemical/biological. These literacy practices include the textual genres that the engineers read and/or write, the frameworks that the engineers employ when interpreting or evaluating a text, and the situated social activities in which the genres and frameworks are embedded. The knowledge gained about these literacy practices will be translated into a model of DLI in engineering to teach students how to use authentic engineering literacy practices as they learn discipline-specific engineering content.

We recruited two engineers from each of the selected four disciplines of engineering (electrical/computer, mechanical/aerospace, civil/environmental, and chemical/biological) for a total of eight engineer participants. All participants were selected from different engineering companies to ensure a broad range of environments were captured. Furthermore, we recruited engineers whose job functions varied along the product development cycle to capture the various core genres and literacy practices essential to that particular role within the design process. These selection criteria were intended to strengthen the model of DLI in engineering by incorporating practices that are representative of a broad range of engineering job functions that are also authentic to each particular discipline.

\section{Major Activities}

\section{Data Generation}

The primary forms of data collection for this project include in situ, ethnographic observations at each engineers' workplace followed by semi-structured interview and think-aloud protocols. Over the course of six months, we observed each engineer twice per month for two hours. Following the two observations, we then conducted a two-hour interview and think-aloud session once per month in which the engineers recounted their thought processes as they read and 
evaluated a particular text that we observed them using. In total, we conducted 12 observations and six interview and think-aloud sessions with each of the eight engineers. Table 1 provides a summary of the engineer participants, their discipline, and work focus.

Table 1: Summary of the engineer participants in this study.

\begin{tabular}{|c|c|c|c|}
\hline Engineering discipline & Pseudonym & Specialization & Work focus \\
\hline \multirow[t]{2}{*}{ Electrical/Computer } & Allen & Operating system development & $\begin{array}{l}\text { Conceptual development and } \\
\text { field support }\end{array}$ \\
\hline & Barry & Hardware design and testing & Testing and field support \\
\hline \multirow[t]{2}{*}{ Mechanical/Aerospace } & Bart & Analysis and design & $\begin{array}{l}\text { Conceptual and detailed } \\
\text { product design }\end{array}$ \\
\hline & Kara & Process development & Management \\
\hline \multirow[t]{2}{*}{ Civil/Environmental } & Trevor & Municipal engineering & $\begin{array}{l}\text { Project management and } \\
\text { engineering oversight }\end{array}$ \\
\hline & Alice & $\begin{array}{l}\text { Data management, processing, } \\
\text { and control }\end{array}$ & Data management and research \\
\hline \multirow[t]{2}{*}{ Chemical/Biological } & Kendra & Biological process engineering & Management \\
\hline & Brenda & Quality assurance & $\begin{array}{l}\text { Operations management and } \\
\text { continuous improvement }\end{array}$ \\
\hline
\end{tabular}

In Year 1, we collected and analyzed data with the electrical/computer engineers. In Year 2, we collected data from the mechanical/aerospace engineers and analyzed the data from the electrical/computer engineers. In Year 3, we analyzed the data from the mechanical/aerospace engineers, and we have begun collecting data with the civil/environmental engineers and the chemical/biological engineers. As of ASEE 2020, we have completed data collection with the two mechanical/aerospace, two civil/environmental, and two electrical/computer engineers. We are continuing to collect data with our final set of engineer participants in chemical and biological engineering.

\section{Data Analysis}

Analysis of the field notes from the on-site observations and of the interview and think-aloud data is ongoing. This study uses a multiple, comparative case study approach [5] in which each engineer is a bounded case. We used constant-comparative analysis (CCA) techniques [6] to generate initial and focused codes from the field notes taken with each engineer. The initial 
codes represented the different forms of textual genres the engineers engaged with while working. These codes and their respective definitions were then added to the developing codebook. The codebook was revised and refined as additional genres appeared in the observation files. To ensure accuracy in analyzing the observation files, one member of the research team independently coded the files, while a second member of the research team backcoded the same files to establish agreement on the emerging codes.

Analyses of the transcripts from the interview and think-aloud sessions are also ongoing. The research team holds bi-monthly meetings in which each member independently reviews each transcript and generates a set of themes related to the reading and writing practices and cognitive frameworks used by each engineer. These emerging themes inform our interpretation of the evaluative frameworks that engineers use while they read and wrote genres in the context of socially situated activities. After independently reviewing each transcript, the team members then discussed the similarities and differences that were found among each other's perspectives. Preliminary results from the initial round of coding with the mechanical/aerospace and electrical/computer engineers were presented at the 2019 ASEE Annual Conference and Exposition [7].

\section{Ensuring Quality}

\section{Advisory Board Feedback}

Throughout the project duration, our research team held meetings with our project advisory board consultants who have expertise in disciplinary literacy, engineering education, and K-12 engineering education research. The consultants provided feedback on our study design, data generation procedures, and preliminary interpretations from the data to ensure that our perceptions of the engineering literacy practices were accurate. Additionally, our advisory board provided feedback on our codebook and thematic analysis from the interview and think-aloud data.

\section{Engineering Consultant Feedback}

Engineering consultants from each discipline of engineering (one mechanical, one electrical, one civil, one biological) reviewed and provided feedback on our emerging codebook. We revised code names and definitions based on their suggestions to ensure our interpretations were authentic to the nature of the individual disciplines of engineering.

\section{Preliminary Findings}

We have found that the textual genres read by the engineers are more closely tied to the individual disciplines of engineering. For example, Allen, the electrical engineer specializing in software, frequently edited and debugged source codes and validated the results of the source code outputs after making changes depending on the desired functionality and output of the source code. Bart, the mechanical engineer specializing in design, frequently consulted threedimensional CAD models demonstrating the concept and functionality of his company's products. Trevor, the civil engineer, frequently evaluated design review documents as part of his company's formal evaluation of a project's design while also consulting industry design standards to ensure those designs adhered to the necessary performance parameters within his 
industry of work. Lastly, Brenda was heavily involved in ensuring that her company's processes, workflows, and procedures were operating as intended through the use of process management and improvement documents.

Although engineers from different disciplines read different genres, we found that they used similar evaluative frameworks regardless of their disciplines. Additionally, we found they engaged in similar situated social activities. For example, we found that repeatability was an evaluative framework that was used by all of the engineers. Barry described how he wanted to ensure that their hardware could produce the same results in the field as it did during testing:

"And now also we have the capability of understanding how we can duplicate that behavior on the bench so that we don't have to go out into a vehicle in order to be able to perform these types of tests in order to make sure that we're still capable of reaching what it that we want to reach, and if we do change that what we will need to do that."

Similarly, the interpretive framework of history was commonly employed by all of the engineers across the disciplines. For example, Bart described in an interview how he relied on a design's history to work on projects going forward:

"So if I'm doing, there's not a lot, if ever, we do anything that's totally unique and new. So, call that one of the fundamental things of engineering is, see what has been done before. And even if you did it before, you can't remember everything. So whenever doing something similar, I refer back to old reports."

Likewise, the situated social activities in which the genres and frameworks were embedded were also commonly visible across the disciplines. A common social activity was engaging in peer review. This activity included the solicitation and gathering of feedback from customers, team members, or others, depending on the context of the document. Peer review may also occur as the engineers learn new information about the topic they are working on or as they familiarize themselves with any updates to standards or regulations that inform their work. For example, Allen stated he relies on customer feedback in order to identify problems with their products:

"In this case I actually, you know, communicated with...our main guy in England that, you know, is close to the customers and brings up these problems or. And part of that communication at that stage is to try to get more information from the customer."

Similarly, Bart described how part of his company's design review process was to obtain feedback from their customers:

"And then I also do a fair amount of documentation on the analysis. Verify that designs meet various codes and participate in design reviews with customers."

Based on these preliminary results, we envision a model for DLI in engineering where the textual genres are more closely tied to the individual engineering disciplines, and the frameworks and situated social activities are more broadly encountered across the engineering disciplines as whole. We anticipate that the more general literacy practices can be used to inform curriculum 
development at the K-12 level, while the practices more specific to the individual disciplines can inform curricular materials for undergraduate engineering education.

\section{Future Activities}

The data collected and analyzed throughout this project will inform the development of a model of DLI in engineering that can be used by teachers and practitioners in both K-12 and undergraduate educational environments. This model will be translated into standards-aligned instructional materials, including videos, lesson plans, and curricular units, and will be made widely available to ensure that all students have access to high-quality, authentic engineering content. For example, a K-12 science curriculum could be coupled with a model of DLI in engineering to encourage students to use authentic engineering literacy practices to solve gradeappropriate design problems. Similarly, for undergraduate engineering education, DLI could support a problem-based learning (PBL) engineering pedagogy by promoting the use of authentic literacy practices while engaging in the solution process of a complex engineering problem.

\section{Acknowledgements}

Support for this work is provided by the National Science Foundation under Award No. EEC 1664228. Any opinions, findings, conclusions, or recommendations expressed in this material are those of the author(s) and do not necessarily reflect the views of the National Science Foundation. Some of this material is based on work accomplished while serving at the National Science Foundation. 


\section{References}

[1] R. Schoenbach, C. Greenleaf, and L. Murphy, Reading for understanding: How reading apprenticeship improves disciplinary learning in secondary and college classrooms, 2nd ed. San Francisco, CA: WestEd, 2012.

[2] S. Wineburg and A. Reisman, "Disciplinary literacy in history: A toolkit for digital citizenship," Journal of Adolescent and Adult Literacy, vol. 58, pp. 636-639, 2015.

[3] A. M. Hillman, "A literature review on disciplinary literacy: How do secondary teachers apprentice students into mathematical literacy?," Journal of Adolescent \& Adult Literacy, vol. 57, pp. 397-406, 2014.

[4] G. N. Cervetti and P. D. Pearson, "Reading, Writing, and Thinking Like a Scientist," Journal of Adolescent \& Adult Literacy, vol. 55, no. 7, pp. 580-586, Apr. 2012.

[5] R. K. Yin, Case Study Research Design and Methods. Thousand Oaks, CA: Sage, 2014.

[6] R. Thornberg and K. Charmaz, "Grounded theory and theoretical coding," in The SAGE handbook of qualitative data analysis, U. Flitz, Ed. Los Angeles, CA: SAGE, 2014, pp. 153-169.

[7] T. Green, A. Minichiello, and A. Wilson-Lopez, "Developing a Model of Disciplinary Literacy Instruction for K-12 Engineering Education: Comparing the Literacy Practices of Electrical and Mechanical Engineers (Fundamental)," in 2019 ASEE Annual Conference \& Exposition, Tampa, FL, 2019. 